\title{
Comercio
}

\section{transfronterizo de}

ganado en el reino de

la Nueva Galicia

\section{durante el siglo XVII}

Cross-Border Cattle Trade in the Kingdom of the Nueva Galicia during the I7th Century

DOI: https://doi.org/10.22380/20274688.1135

\begin{tabular}{c}
\hline Recibido: 20 de enero del 2020 \\
\hline Aprobado: 12 de marzo del 2020 \\
\hline
\end{tabular}

RENÉ DE LEÓN MEZA*

CUCEA, Universidad de Guadalajara

leonmeza@yahoo.com

\section{R E S U M E N}

Este artículo estudia cómo se desarrolló la crianza de ganado mayor de manera intensiva en el reino de la Nueva Galicia durante el siglo xviI, lo que permitió cubrir fácilmente la demanda interna de consumo y orientar sus excedentes a otros mercados de la Nueva España. Con datos cuantitativos se destaca la relevancia económica que adquirió la exportación de ganado mayor para el reino neogallego y se analiza, en contraste, la poca crianza de ganado menor en aquella jurisdicción, pero lo bien abastecida que estuvo de esos animales gracias a la llegada de numerosos rebaños a sus límites fronterizos, donde eran adquiridos y luego introducidos para su consumo en las principales ciudades y reales de minas.

Palabras clave: ganado, exportación, importación, fronteras, iglesia

* Doctor en Historia del Colegio de México; profesor investigador de la Universidad de Guadalajara, Centro Universitario en Ciencias Económico-Administrativas, Departamento de Ciencias Sociales y Jurídicas. Investiga la formación de los circuitos comerciales en la Nueva Galicia durante los siglos XVI-XVII. Analiza la evolución y especialización productiva de la tierra en el reino neogallego durante la época colonial. ORCID: 0000-0002-5577-0438. 


\section{$\begin{array}{llllllll}\mathbf{A} & \mathbf{B} & \mathbf{S} & \mathbf{T} & \mathbf{R} & \mathbf{A} & \mathbf{C} & \mathbf{T}\end{array}$}

This article studies how in the kingdom of Nueva Galicia the breeding of cattle was developed intensively during the seventeenth century, wich allowed it to easily cover domestic consumption demand and orient its surpluses to other markets in New Spain. Stresses with quantitative data the economic relevance acquired by the export of cattle to the neogallego kingdom. In contrast, it analyzes the small rearing of small livestock in that jurisdiction but how well stocked these animals were thanks to the arrival of numerous herds at their border limits where they were acquired and introduced for consumption in the main cities and real mines.

Key words: cattle, export, import, borders, church

\section{Introducción}

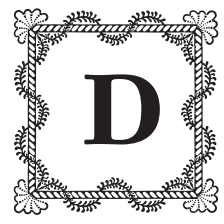

urante años he venido afirmando que la historiografía del reino de la Nueva Galicia es muy escasa, en particular para los siglos XVI y XVII, con una abundancia de temas pendientes para su estudio y análisis. La ganadería colonial temprana es un ejemplo de lo anterior pues no hay un solo libro que la analice. La obra del profesor Serrera es un espléndido trabajo, pero se enfoca en el siglo XVIII. Los estudios de Thomas Calvo que analizan el siglo Xvir abordan el tema ganadero y resaltan su importancia para el consumo interno, además de destacar las actividades ganaderas de algunos criadores de animales. Van Young en su estudio sobre Guadalajara y su región, en el cual analiza el último cuarto del siglo Xvir, insinúa la importancia económica que tuvo la exportación de ganado. Todas estas obras, además de su valioso aporte, tienen algo en común: fueron escritas hace más de veinte años. Desde entonces no se conoce otra obra publicada que estudie la ganadería neogallega del siglo XVII.

El objetivo de este artículo es analizar un aspecto novedoso de la historia ganadera del reino de la Nueva Galicia que consiste en la formación y el funcionamiento del circuito comercial establecido por la exportación de ganado mayor y la importación de ganado menor, entendiendo estos conceptos como la salida o llegada de animales más allá de los límites geográficos establecidos para ese reino. Para ello, explica las fronteras con la Nueva España y con la provincia de Ávalos, jurisdicciones implicadas en esta actividad comercial. Se resalta que 
todos estos espacios pertenecían a la Corona española, pero que se manejaban administrativamente de forma independiente uno del otro.

En esencia, lo que este trabajo plantea es que en el reino de la Nueva Galicia la ganadería se desarrolló de manera intensiva, en particular la del ganado mayor, lo que permitió satisfacer fácilmente la demanda interna y orientar sus excedentes a otros mercados de la Nueva España. El ganado menor tuvo en cambio un proceso de introducción más lento, mas no por ello hubo desabasto de esos animales pues año con año llegaban a pastar a sus inmediaciones enormes rebaños y ahí acudían los encargados del abasto de carne para comprarlos e introducirlos a Guadalajara y otras provincias.

Se plantea asimismo la hipótesis de que la relevancia económica que alcanzó este circuito mercantil indujo a las autoridades municipales y de la Real Audiencia de Guadalajara a establecer la imposición de nuevos impuestos, como el de "pastoreo" y el de "saca de ganado". Gravámenes que a ningún otro producto que salía o entraba a la Nueva Galicia se le cargaron. Se sostiene además que lo lucrativo de la exportación de ganado mayor ocasionó que las autoridades eclesiásticas del obispado de Guadalajara no solo se insertaran en este negocio, sino que se convirtieron en las principales exportadoras. Lo anterior a pesar del constante discurso opositor que pregonaban respecto a la saca de ganado.

El presente trabajo se sustenta en una amplia gama de fuentes documentales, casi todas inéditas, provenientes del Archivo de Instrumentos Públicos de Guadalajara, de la Real Audiencia de Guadalajara, del Archivo General de Indias y del Instituto Cultural Ignacio Dávila Garibi de la Cámara de Comercio de Guadalajara.

\section{La configuración territorial del reino de la Nueva Galicia}

Cuando en I53I se erigió la gobernación de la Nueva Galicia, el territorio que la conformaba era muy impreciso, sobre todo hacia la zona norte donde prácticamente no había frontera. Por el sur también hubo complicaciones debido a la disputa por los territorios entre los conquistadores Hernán Cortés y Nuño Beltrán de Guzmán. Por el occidente no se presentaron problemas pues sus límites los marcó todo el litoral del océano Pacífico, mientras que por el oriente quedaron bien definidos con la Nueva Espańa. En 1548 cuando esa gobernación se transformó en reino, dotándosele de una audiencia subordinada a la de 
México, sus límites quedaron mejor definidos. Sin embargo, fue sobre todo en 1574, cuando se le otorgó el grado de cancillería, con independencia en lo judicial y administrativo, que su territorio quedó formalmente definido, y así se mantuvo sin cambios sustanciales hasta la aplicación de las reformas borbónicas en 1786 (Fernández; Parry).

Para el siglo que aquí se analiza existen dos fuentes que detallan las fronteras entre los reinos de la Nueva Galicia y Nueva España y la provincia de Ávalos. Es verdad que hay una gran diferencia entre ambas fuentes en lo referente a la extensión del reino neogallego, pues la primera, escrita por el obispo Alonso de la Mota y Escobar en 1605, afirma que medía de sur a norte 200 leguas y de oriente a poniente entre 60 y 70 leguas (De la Mota y Escobar 27). En cambio, la descripción de Domingo Lázaro de Arregui elaborada en I62I establece en I5O leguas su longitud (Arregui 73). Esa enorme diferencia se debe a lo impreciso de los límites por la parte norte, donde hacía frontera con los reinos de Nuevo León y Nueva Vizcaya. Para el objetivo de este trabajo ambas descripciones son fundamentales pues coinciden con sus límites por el sur y por el occidente, que son la provincia de Ávalos y la Nueva España. En el mapa i se pueden apreciar claramente las fronteras antes mencionadas.

Es importante aclarar que la provincia de Ávalos, a pesar de su cercanía con la capital neogallega, no perteneció administrativamente a Nueva Galicia sino a Nueva España. Solo los asuntos judiciales sí se resolvían en la Audiencia de Guadalajara. Lo anterior conllevó un estatus de cierta independencia o confusión entre ambas que solo se resolvió en el último tercio del siglo XviII con la creación de las intendencias. Por eso, siempre se le menciona como un territorio aparte entre ambos reinos, y en este trabajo tiene un papel destacado pues por ahí se realizará la importación de ganado menor para la Nueva Galicia.

\section{Origen y desarrollo de la ganadería en Nueva Galicia}

El extenso territorio que conformó el reino de la Nueva Galicia tuvo las condiciones óptimas para el desarrollo exitoso de la ganadería. Abundantes tierras, ricas en pastizales y fuentes de agua fueron el primer factor natural para la conformación de estancias ganaderas donde se criaba en exceso el ganado vacuno, mular y caballar. No obstante, fue la demanda de esos animales lo que detonó su crianza intensiva. Los primeros mercados consumidores importantes fueron 


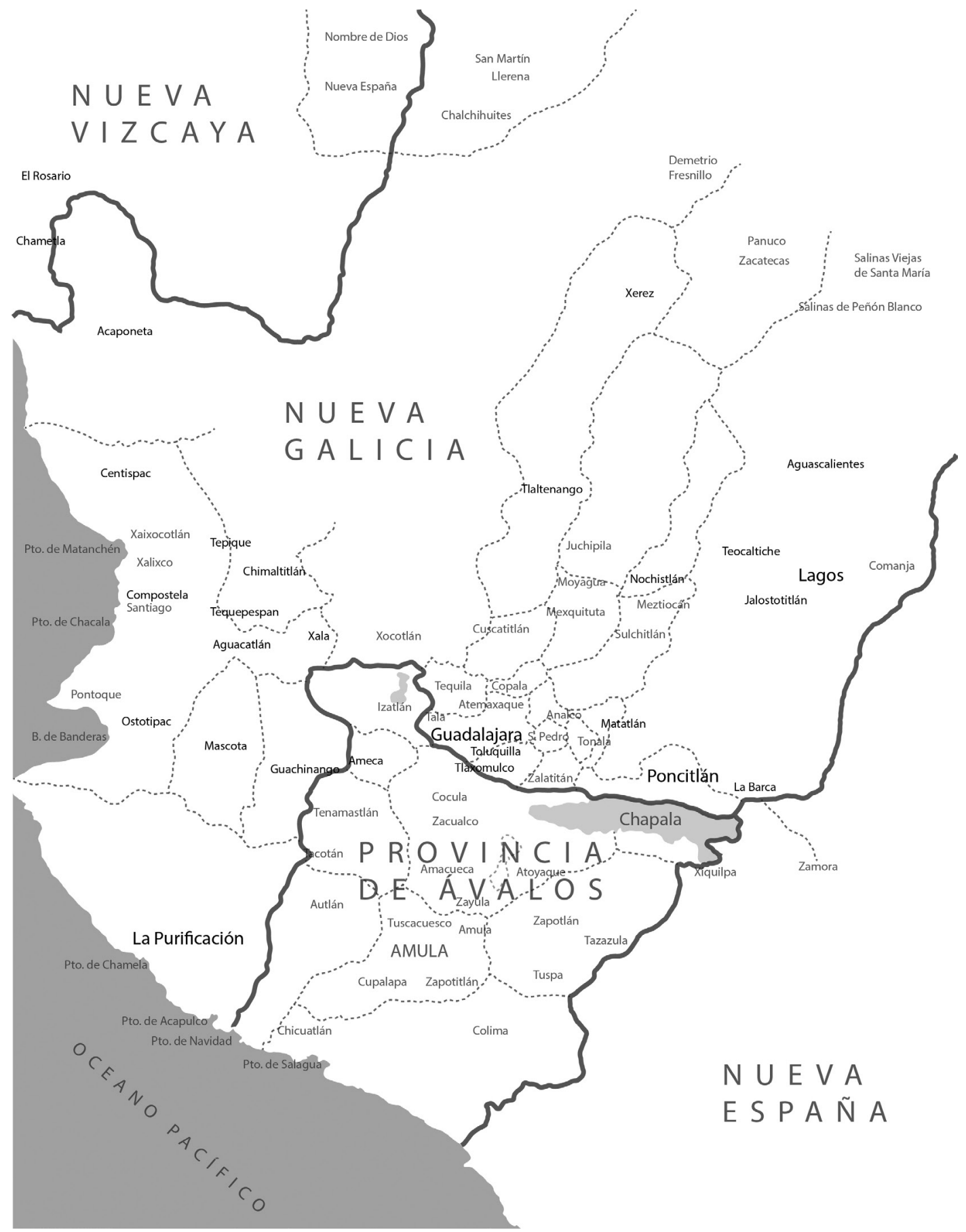

$\rightarrow$ MAPA I

La Nueva Galicia y sus fronteras en el siglo XVII

Fuente: elaboración propia a partir de Acuña (9) 
los numerosos reales de minas que se descubrieron desde mediados del siglo XVI y que se mantuvieron en activo durante toda la época colonial. Muy pronto la oferta sobrepasó la demanda del mercado interno de la Nueva Galicia y desde el último tercio de aquella centuria se comenzó a exportar a otros mercados mayores, como Michoacán, Querétaro, Guanajuato, San Luis Potosí, Toluca, Ciudad de México y Puebla.

El gran negocio que representaba la crianza y venta del ganado mayor, tanto para el consumo interno como para el externo, potenció la configuración de varias zonas ganaderas, siendo el clima un factor fundamental para la especialización en la crianza. Así, vemos que en regiones de climas cálidos y húmedos el ganado vacuno fue mayoritario, mientras que en los fríos abundó el mular y el caballar.

En la parte norte del reino, en los trece pueblos que conformaban la alcaldía mayor de Juchipila y el corregimiento de Nochistlán, había más de 50.000 cabezas de ganado y cada año se herraban 7.50o becerros. En la de Tlaltenango y Jeréz, que incluía a los pueblos de Jalpa, Mecatabasco, Moyagua y Mesquituta, el número de becerros herrados anualmente era de 4.000 y el de ganado menor de $3.000^{\mathrm{I}}$. La región, que hoy identificamos como los Altos de Jalisco, fue una de las más ricas criadoras de ganado. Abarcaba desde Zapotlán de los Tejuexes, incluía Tepatitlán, Jalostotitlán, Teocaltiche y llegaba hasta Santa María de los Lagos y Aguascalientes. En estos últimos dos lugares, el promedio anual de becerros herrados a fines del siglo xvi fue de 50.000. En la segunda década del xviI, en las diez haciendas ganaderas que había en Aguascalientes, se herraban cada ańo 22.000 mil becerros, mientras que en las quince estancias de Lagos, poco más de 20.000 (De la Mota y Escobar 58; Berthe, Calvo y Jiménez 4I, I37-I38).

En las haciendas que se ubicaban dentro de un radio de $60 \mathrm{~km}$ alrededor de Guadalajara abundaba el ganado mayor. Tan solo en los años de 1595 y 1596 se herraron en cada una 23.000 becerros, además de las mulas y caballos que no se contabilizaron (Berthe, Calvo y Jiménez 4I). En todo el corregimiento de Tlajomulco se herraban anualmente de 5.000 a 6.000 becerros y más de 400 mulas (Arregui I2I). En Tala, el dueño de la hacienda Los Cuisillos tenía I6.03I cabezas de ganado mayor que le permitían herrar anualmente de 3.000 a 4.000 becerros y "muchas mulas" (Arregui I22; AIPG, LG, "Francisco de Orendain", vol. I, ff. 255-257 v.).

I Estas cifras fueron calculadas por el visitador Gaspar de la Fuente cuando recorrió aquellos lugares entre i608 y i609 (Berthe, Calvo y Jiménez i I 4-I27). 
Rumbo al poniente de Guadalajara, como a unos $70 \mathrm{~km}$, iniciaba el valle de Ameca. Allí, en el primer tercio del siglo xvir, Luis de Ahumada poseía más de 50.000 cabezas de ganado mayor y menor. En las siguientes 12 leguas hasta llegar a Guachinango se formó un corredor ganadero en el que existieron muchas estancias de ganado mayor y criaderos de mulas (De la Mota y Escobar 32, 36). En las cercanías de la ciudad de Compostela se criaban muchas vacas, mulas, ovejas y cerdos. En el valle de Banderas también se daba esta crianza, mientras que en los valles de Jaltemba y Chila solo ganado vacuno. Uno de los mayores centros de crianza de mulas quedaba en el pueblo de Tequepexpan, donde también había muchas estancias de ganados mayores. Más hacia el noroeste estaban Tepic, Centispac y Acaponeta que conformaron la región más importante de exportación de ganado mayor.

La especialización en la crianza de ganado que alcanzaron algunas regiones ocasionó que abandonaran cualquier otra actividad económica para dedicarse en exclusivo a la ganadería. Lagos de Moreno y Aguascalientes son los casos más representativos. Los habitantes del primero se dedicaron al inicio de su fundación (I560) al cultivo del trigo y el maíz, pero conforme se fue introduciendo la ganadería, esta en pocos años sustituyó por completo la actividad agrícola. De tal modo, a principios del siglo XVII los ganaderos de Lagos importaban maíz, trigo y harina de distintos lugares (De la Mota y Escobar 55-56). Un caso idéntico fue el de Aguascalientes, donde según Mota y Escobar no se sembraba ni cosechaba ninguna clase de granos y sus habitantes solo se dedicaban a la crianza de vacas, mulas y caballos (De la Mota y Escobar 58).

\section{El comercio de exportación de ganado mayor}

Desde finales del siglo xvi el ganado mayor se había convertido en el principal producto de exportación de la Nueva Galicia. Su relevancia económica implicó directamente a las autoridades civiles y eclesiásticas que tuvieron un papel relevante en la administración y funcionamiento de este negocio. De manera institucional, los distintos obispos de Guadalajara y sus cabildos eclesiásticos se opusieron constantemente a la extracción de ganado que repercutía negativamente en la recaudación del diezmo y por lo tanto en sus ingresos personales. En 1606 comenzaron a presionar al rey a través de cartas e informes para que emitiera una cédula que prohibiera la saca y matanza de vacas. En ellas le 
exponían la precaria situación en la que vivían los prebendados a causa de que habían disminuido los diezmos (ICDG, GDL 64 I2 SL, I606).

En particular, el obispo Alonso de la Mota y Escobar detallaba cómo en los últimos seis años se había incrementado la exportación de vacas. Ponía como ejemplos al gobernador de la Nueva Vizcaya, Rodrigo de Río, que en una ocasión sacó más de 60.000 cabezas; al capitán Francisco de Urdiñola, que junto a otros habían prácticamente despoblado el valle de Zapotepec, ubicado en los contornos de Guadalajara, pues exportaban más de 20.000 novillos al año (Dávila, t. 2, I52-I53). En I609 el deán y el Cabildo de Guadalajara expusieron ante el Consejo de Indias la grave escasez de ganado vacuno en toda la Nueva Galicia, debido a que la mayoría se exportaba a la Nueva España, lo que ocasionaba una gran disminución en las rentas decimales (ICDG, GDL 46 20, I609). Dos años después, el siguiente obispo acusaba ante el rey a los oidores por otorgar a sus allegados numerosas licencias para la extracción de animales (ICDG, GDL 56 24, I6II). El cabildo eclesiástico continuó arremetiendo contra la saca de ganado y en I618 escribió al Consejo de Indias para acusar a varios gobernadores de la Nueva Galicia de repartir permisos para la saca de vacas entre sus familiares y amigos (Dávila, t. 2, 208). No obstante las numerosas quejas, solo se conoce una orden del rey dirigida en I648 a la Audiencia de Guadalajara para que limitara el número de licencias de extracción y fomentara la crianza de vacas (ICDG, GDL 56 46, I648).

Por su parte, la Audiencia de Guadalajara, ante las enormes cantidades de animales que salían año con año rumbo a la Nueva España, se vio obligada a implementar un sistema de registro y cobro de impuestos sobre esa actividad. El 22 de septiembre de 1600 determinó que los criadores de ganado mayor de Lagos y Teocaltiche no pudieran sacar sus animales sin registrarlos ante la justicia más cercana y demostraran que eran de ellos. Nombró a un juez que junto con un escribano y alguacil debían hacer el registro y cobro que se estipuló en 2 pesos por cada roo cabezas.

En I602 el gobernador de la Nueva Galicia, Santiago de Vera, amplió ese reglamento para que sin expresa licencia otorgada por él o sus sucesores, no se pudiera sacar animal alguno para la Nueva Espańa. Los que lo hicieran serían multados con io pesos por cada cabeza que intentaran sacar, más 500 pesos. Cuatro años más tarde, el visitador Juan Paz de Vallecillo emitió en la villa de Lagos las primeras ordenanzas en las que ratificó los dos autos anteriores y mandó que los 2 pesos asignados por el registro de cada Ioo reses se repartieran, dándole 6 reales al juez, 6 al escribano y 4 a una persona que conociera de los hierros de 
los criadores. La tarifa por exportación de ganado se mantuvo fija hasta que en I649 el presidente de la Audiencia de Guadalajara, Pedro Fernández de Baeza, decidió aumentarla a 4 pesos por el primer ciento y 2,5 por cada centenar extra; esta se mantuvo el resto del siglo (AGI, CA, Guadalajara 27 RI N IO).

Además del impuesto, los oficiales fiscales de aquella audiencia establecieron en 1604 un centro de registro para el ganado que sería exportado. Para ello, se buscó un lugar que estuviera en el límite territorial entre ambos reinos. La idea era que existiera nada más uno que tuviera los corrales necesarios para poder contar los animales. Toluquilla fue el seleccionado y durante algún tiempo funcionó exclusivamente. Se pretendía que el trámite no durara más de tres días (AGI, Guadalajara, $C A, 7$ R2 N I2), pero como el ganado era numeroso se escogieron otros dos lugares que fueron Lagos y Aguascalientes. A esos tres centros debían acudir todos los acarreadores para registrar su nombre, cantidad y tipo de ganado, el origen de este, a quién pertenecía y el destino. Además del juez y escribano, estaban presentes en el registro un representante del cabildo civil, otro del eclesiástico y el obligado de las carnicerías de cada ciudad. Ante ellos se verificaba que entre los animales que se sacara no fuera ninguna vaca ni ternera.

El transportista contaba con un periodo máximo de sesenta días para sacar el ganado, de lo contrario necesitaría tramitar un nuevo permiso. Este proceso administrativo tenía lugar en los meses de julio a septiembre, justo en pleno temporal de lluvias. Esto permitía que los animales engordaran hasta quedar listos para la travesía y durante esta aprovechar la formación de aguajes y abundancia de pastos a lo largo del trayecto para que los animales llegaran lozanos a su destino y así se cotizaran a buenos precios.

En el siglo XVII existieron varias formas de exportación de ganado. Una de ellas fue a través de la participación directa de los criadores en el traslado y venta de los animales. Otra funcionaba mediante agentes o intermediarios que trasladaban el ganado a cambio de un porcentaje de las ganancias obtenidas en la venta final. Una más se dio a través de los comerciantes que se dedicaban a comprar ganado al menudeo recorriendo diferentes estancias ganaderas para después exportarlos para su reventa.

En el primer formato destaca para la segunda mitad del siglo Pedro de Ávalos y Bracamonte, descendiente de conquistadores que había heredado grandes extensiones de tierra, las cuales amplió gracias a varias mercedes de estancias para ganado mayor que consiguió en la década de i650. Entre los años de i669 a I680 exportó desde sus haciendas ubicadas en Compostela a la Ciudad de México 28.I35 novillos, toros y torunos, un promedio anual de 2.557 cabezas (AIPG, $L G$, 
vols. I-3; AIPG, TA, vols. 356 y 363). A fines del siglo XVII y principios del XVIII, su hijo Alonso acrecentó la riqueza y actividad comercial. La exportación de ganado continuó siendo una de las más importantes entradas de capital para esta familia, pues entre 176I y I797 llevó a la Ciudad de México 36.855 cabezas de ganado (Serrera, Guadalajara I38-I39).

Otros ganaderos que vendían directamente sus animales en la Ciudad de México fueron el capitán Francisco de Galindo, quien desde su hacienda de Tetitlán, ubicada en la jurisdicción de Tequepexpan, exportó, en siete años, I8.050 cabezas de ganado vacuno, y Diego de la Mota y Padilla, criador en Jalostotitlán que en la última década del siglo envió a esa misma ciudad un total de 26.960 cabezas, de las cuales 22.700 eran novillos, toros y torunos, I.550 caballos y 2.700 mulas (AIPG, $L G$, vol. 70; AIPG, TA, vols. 358 y 37I).

La otra forma de exportación estuvo controlada por comerciantes que se enriquecieron comprando ganado en el interior y llevándolo a revender a la Nueva Espańa. Durante la primera mitad del siglo el más destacado fue el maestre de campo Francisco de Pareja y Rivera. La forma en que funcionaba su red comercial se basaba en hacer muchas compras al menudeo, sobre todo de animales recién nacidos. Sus vendedores estaban repartidos por todo el territorio de la Nueva Galicia, desde Acaponeta y valle de Banderas en el noroeste hasta Sayula en el sur, pasando por Guadalajara. Contaba con tres lugares estratégicos (Aguacatlán, Magdalena y Toluquilla) donde le entregaban el ganado que él mismo engordaba. Una vez que reunía muchas cabezas, contrataba a un grupo de rancheros que se encargaban de trasladarlas a la Ciudad de México para su reventa (AIPG, "Francisco de Orendain", vols. I-3).

Por los contratos que establecía con los acarreadores de su ganado, se conoce la magnitud de su negocio. En I629 firmó un convenio por varios viajes con un experimentado sacador de bovinos de la ciudad de Guadalajara. Cada viaje se haría con un mínimo de 3.500 cabezas y un máximo de 4.000. La tarifa por el traslado se fijó en 3 reales por animal, lo que da una cantidad de entre I.3I2 y I.500 pesos. A cambio, el acarreador se responsabilizaba a pagar 6 pesos por cada novillo que no llegara a su destino. La mercancía se entregaba en los alrededores de la Ciudad de México, a una distancia de I2 leguas $(48 \mathrm{~km})$. El acarreador se comprometía una vez llegado a su destino, a mantener bajo su cuidado a los animales hasta por 20 días. Posteriormente, el dueño de ellos le pagaría Ioo pesos por cada mes que se tardara en venderlos (AIPG, "Francisco de Orendain”, vol. I, ff. 316-317 v.). El profesor Thomas Calvo escribió que Francisco de Pareja vendía entre 7.000 y 10.000 bovinos sin contar las mulas y 
caballos. Esta actividad comercial fue tan exitosa para este "señor de ganados", que al momento de su muerte se contaron entre sus pertenencias 20.116 novillos, I.082 mulas y 249 potros (Calvo, Guadalajara 289).

Entre los que se dedicaron exclusivamente al negocio de trasladar ganado ajeno está el comerciante japonés Juan de Páez, que representaba al mismo tiempo los intereses del cabildo eclesiástico de Guadalajara y de uno de los ganaderos más ricos de Compostela. Entre I660 y I674 exportó I8.873 novillos, toros y torunos; II.773 eran de un ganadero de Compostela y el resto del cabildo eclesiástico que había recolectado de diezmo. Fue un agente comercial del obispado de Guadalajara donde se desempeñaba como mayordomo y administrador de los diezmos y rentas de la catedral (AIPG, $L G$, vols. I-3). Sus contactos con comerciantes de la Ciudad de México le permitían, a diferencia de otros exportadores de ganado, vender de manera rápida los animales que trasladaba y evitarse gastos en la renta de estancias para guardarlos y alimentarlos mientras los vendía (anexo I) ${ }^{2}$.

La exportación de ganado de la Nueva Galicia está estrechamente vinculada al papel relevante que tuvo la iglesia de Guadalajara como vendedora, a pesar de que en sus discursos se proclamaba opositora a la saca de animales. Tanto el cabildo eclesiástico como los conventos, colegios, curas, vicarios, entre otros, fueron exportadores de ganado. El vínculo entre Iglesia y exportación de ganado lo encontramos en el diezmo pues a lo largo del siglo Xvir el formato que predominó en aquel obispado fue el de arrendar el derecho de recolección a particulares, aunque en muchos curatos la Iglesia lo hacía directamente. En términos generales, los productos principales eran granos y animales. Los primeros los vendía para el mercado interno y los segundos los exportaba. El mayordomo del obispado era el encargado de realizar esas ventas, pero antes tenía que engordar y criar a los animales del diezmo. Para ello contrataba a expertos ganaderos y cuando ya estaban crecidos ellos mismos los vendían y exportaban.

Eso hizo el licenciado Francisco de Quijada cuando administró algunos curatos entre 1657 y I684. Concentraba a los animales recaudados para su crianza en haciendas cercanas a Guadalajara y luego enviaba la mayoría de ellos a la Ciudad de México para su venta; fue muy poco lo que vendió en el interior, probablemente por los mejores precios que alcanzaba en el exterior. En de Guadalajara, no así su actividad como exportador de ganado que hemos señalado (Calvo, "Japoneses" 533-547). 
una ocasión, en 1672 , vendió a un vecino de Querétaro 800 novillos que había recolectado de los diezmos de Autlán y Guachinango cuatro años atrás, por los que había recibido 3.600 pesos ${ }^{3}$.

Por un contrato que firmó Francisco Quijada ese mismo año con un criador de ganados, se pueden esbozar las ganancias de la Iglesia cuando vendía sus animales ya convertidos en novillos. Quijada había recolectado I.60o becerros de los curatos de Autlán y Puertos Bajos para los años de i671 y i672. El trato consistía en que un ganadero de Colimilla y Matatán se los criaría hasta los cuatro años. Por este servicio, Quijada le pagaría un peso por cabeza, la mitad en efectivo y la otra con becerros de dicho diezmo a razón de 12 reales cada uno, más seis becerros por cada ciento a manera de refacción por las posibles pérdidas (AIPG, "Tomás de Orendain”, vol. 4, ff. 26-27.). Así, el costo de crianza le saldría en poco más de I.70o pesos. Si los llegara a vender al mismo precio que había vendido los anteriores (4,5 pesos por cabeza), le quedaría una ganancia de 5.500 pesos. En los años posteriores, Quijada continuó exportando ganado mayor proveniente del diezmo de Guachinango, Jalisco, Centispac y Acaponeta hacia la Ciudad de México (AIPG, "Tomás de Orendain”, vol. 4, ff. 26-27; AIPG, TA, vol. 363, f. 239 v.).

Los exportadores eclesiásticos que más destacaron fueron los jesuitas de Guadalajara. Ellos poseían las haciendas ganaderas de Santa Catalina, Jalisco, Guaristemba y Guimaraes, ubicadas en Compostela y Tepic, así como de la de Toluquilla en las inmediaciones de Guadalajara. De estas cinco posesiones salieron para la Nueva España 34.653 cabezas de ganado entre I673 y i693. De hecho, la partida más numerosa que se tiene registrada fue realizada por los jesuitas en el año de I687, cuando de su hacienda Santa Catalina, en Tepic, salieron rumbo a México 7.600 novillos, toros y torunos (AIPG, $L G$, vol. 6, exp. 126, ff. 263 v.-264 v.). En segundo lugar encontramos al cabildo eclesiástico de Guadalajara, que en un periodo de trece años (entre I675-1690) exportó 30.690 animales recolectados por concepto de diezmo. De los años que tenemos registrados destaca el de 1675 cuando exportó 5.Ioo bovinos en varias partidas (AIPG, TA, vol. 363 f. 45 v.).

Entre los arrendatarios de diezmos encontramos a varios personajes que eran miembros de la Iglesia y exportaban ganado. El más relevante fue sin duda de Orendain, vol. 4, f. 28 v.). 
el bachiller clérigo presbítero Alonso Jiménez de Sea, quien aprovechando su posición como capellán del presidente de la Audiencia de Guadalajara se dedicaba a comprar los derechos de recolectar diezmos en diferentes lugares, a veces de forma fraudulenta. En I685, por ejemplo, tras intimidar a los demás postores, obtuvo el remate de tres diezmatorios. Los postores perjudicados por tales acciones presentaron su queja ante el obispo quien invalidó la subasta (Calvo, Guadalajara 245). Años después, cuando ya era comisario del Santo Oficio de la Inquisición, obtuvo los derechos para cobrar el diezmo en el partido de Teocaltiche desde 1692 hasta I698. En esos ańos exportó la cantidad de 7.00o bovinos, todos procedentes del diezmo (AIPG, LG, vols. 8, IO, I2-I y I3, exps. 71, 92, 30 y 65, respectivamente).

Si juntamos aquí al resto de miembros de la Iglesia e instituciones eclesiásticas que no hemos mencionado, pero que participaron de manera activa en la exportación de ganado durante los últimos treinta años del siglo XVII, sumaríamos la cantidad de 24.270 bovinos exportados, de los cuales 6.456 corresponden al convento de San Francisco, a las religiosas de la Concepción de Jesús y a las niñas de la Congregación de Jesús Nazareno, todas de Guadalajara. El resto se reparte en una gama de clérigos, vicarios y curas eclesiásticos que eran criadores de ganado en La Barca, Jalostotitlán, Aguascalientes, San Cristóbal, Sierra de Pinos, La Purificación y Guadalajara.

Al sumar todas las cantidades de animales que sacaron los distintos miembros e instituciones de la Iglesia en el periodo aquí estudiado, el resultado es de 96.613 cabezas. El total general que hemos sumado de todas las partidas de saca de ganado entre I670 y 1700 es de 618.462 animales, de modo que el porcentaje exportado por la iglesia de Guadalajara es de $15,62 \%$, lo cual la convierte en la exportadora número uno de toda la Nueva Galicia.

En cuanto a las exportaciones de animales, a partir de las sumas anuales y por regiones, hay un total de 29 años del periodo que abarca de 1670 a I700; solo faltan datos para los años de 1683 y i688. El total exportado en ese tiempo alcanzó la suma de 618.462 cabezas. El $90 \%$ (556.640) fue de bovinos y el resto (6I.822) de mulas y caballos ${ }^{4}$. Al observar la representación gráfica de la exportación de ganado, se advierte claramente la fluctuación que había año con año, sobre todo de 1670 a 1679 cuando las cifras varían de 20.000 a 5.280 cabezas. Se aprecia una tendencia ascendente, con un considerable aumento a partir de

4 En el anexo i aparecen más años, pero como las cifras son muy incompletas solo se analizan de I670 a 1700 . 
I68I, cuando las cantidades sobrepasan los 20.000 animales, sobresaliendo el año de 1695 como el de mayor exportación con 34.340 animales. Inicia luego una tendencia descendente que llega a su punto más bajo en 1699 con solo 7.750 cabezas exportadas.

\section{Cabezas de ganado}

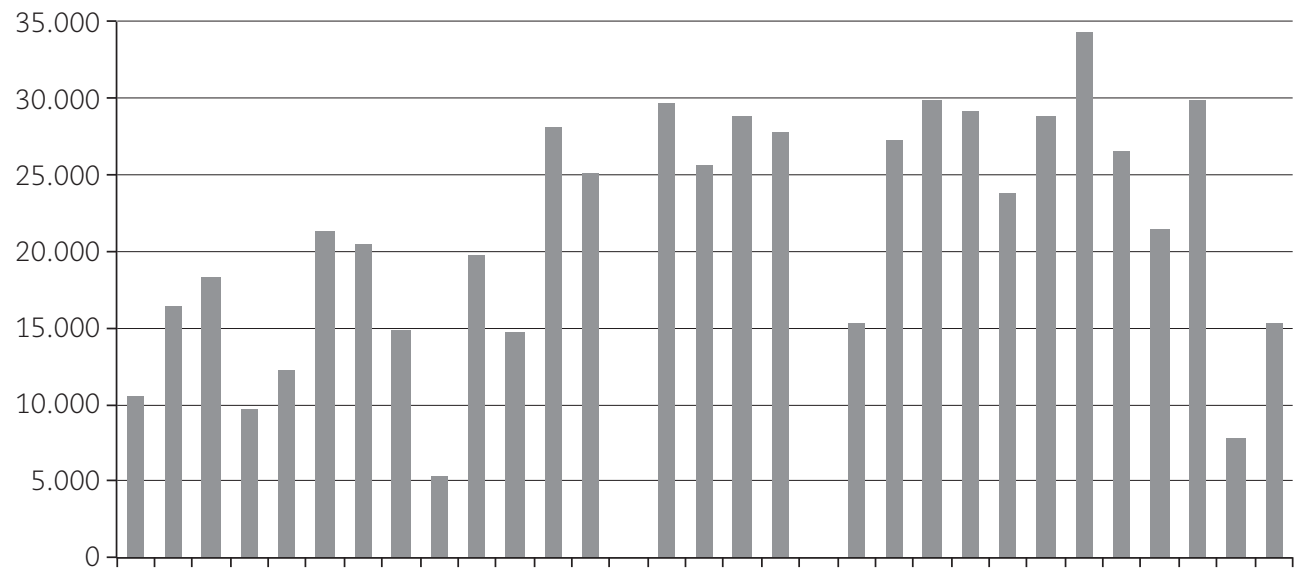

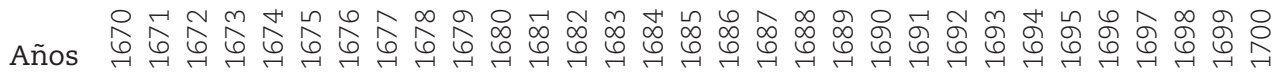

\section{$\leftrightarrow$ FIGURA I.}

Exportación de ganado mayor de la Nueva Galicia, I670-1700

Fuente: AIPG, LG.

La explicación de estas fluctuaciones en la exportación puede hallarse si se consideran los tiempos naturales de crianza de los animales, así como las cantidades de estos recolectadas por el diezmo, pero también la sospecha de que para algunos años la información de los archivos está incompleta. En todo caso, en la figura i se intenta mostrar exclusivamente el alto número de animales que se exportaban de la Nueva Galicia.

El profesor Van Young señala que en 1699 se inició un periodo de recesión en la exportación de ganado que duró hasta I7Is (Van Young 206). Sin embargo, las fuentes documentales utilizadas para este artículo no muestran ningún indicio de esa recesión, aunque es verdad que en el año de i70o el número de cabezas exportadas apenas fue de 15.380. Muy por debajo que los ańos anteriores, pero consideramos que se debe más a la ausencia de registros de licencias pues los libros de gobierno de la Audiencia de Guadalajara de esos años están incompletos. 
En cuanto a las regiones exportadoras de ganado mayor, la más importante estaba en el noroeste de la Nueva Galicia. De nueve poblaciones (Tepic, Compostela, Tequepexpan, Jala, Aguacatlán, Centispac, Acaponeta, Chametla y El Rosario) se sacaron 248.288 cabezas, que representan el 40,I \% del total exportado. La segunda región se ubicaba en el noreste, de donde se exportaron I8I.3I7 cabezas que equivalen al 29,3\%. Es de destacar en esta parte las poblaciones de Lagos, Aguascalientes, Jalostotitlán, Teocaltiche y Juchipila. La tercera región la ubicamos en el centro del territorio, donde se encuentra Guadalajara, Tacotán, La Barca, Colimilla y Matatán, que vendieron I22.I75 animales (19,7\%). El resto lo completa la zona del suroeste en las poblaciones de Guachinango, Ostotipac y La Purificación, con un 3,9\% y un $7 \%$ que representan 40.039 animales que no se puede especificar de dónde salieron, pues la fuente no lo indica.

El más importante centro exportador de ganado fue Tepic con 7I.4IO cabezas, seguido de Compostela con 67.288 animales. En tercer lugar aparece Lagos con 66.220 , en tanto que los lugares cuarto y quinto los ocupan Guadalajara con 57.360 y Acaponeta con 44.I0o cabezas, respectivamente, como se aprecia en la figura 2.

Cabezas de ganado

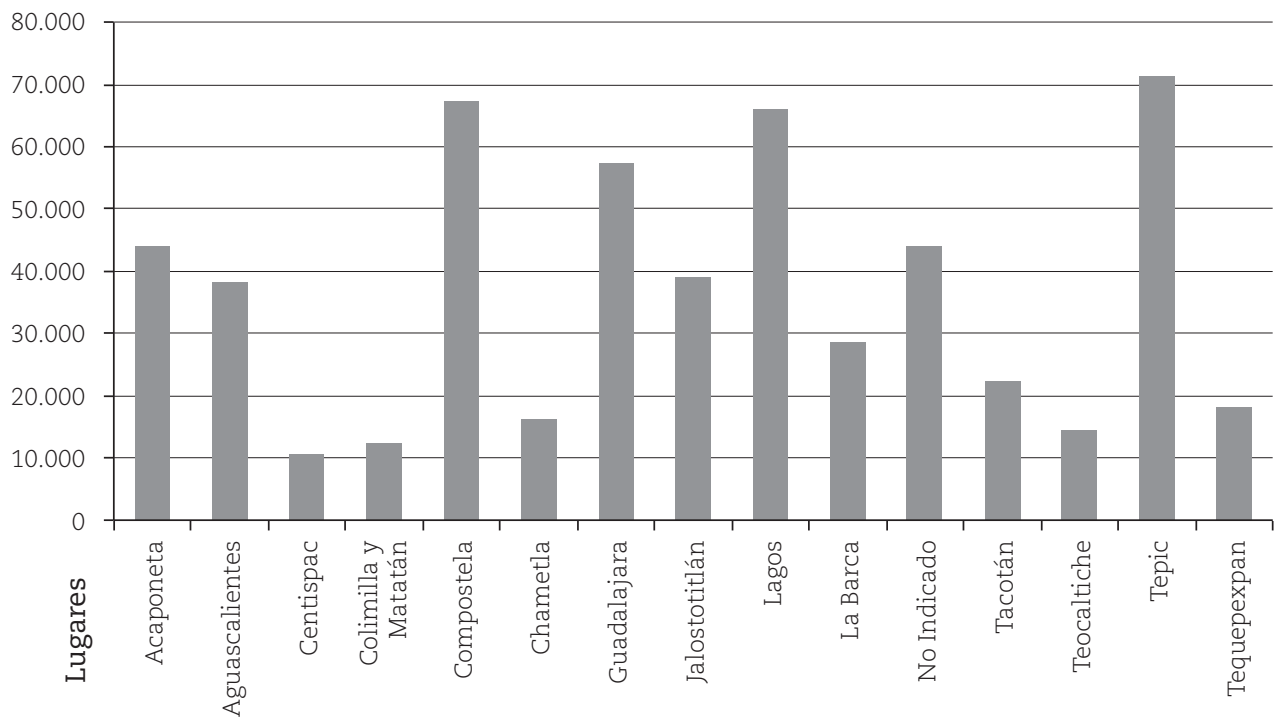

$\rightarrow$ FIGURA 2 .

Principales jurisdicciones exportadoras de ganado de la Nueva Galicia, I670-I700

Fuente: AIPG, LG, Real Audiencia de Guadalajara. 

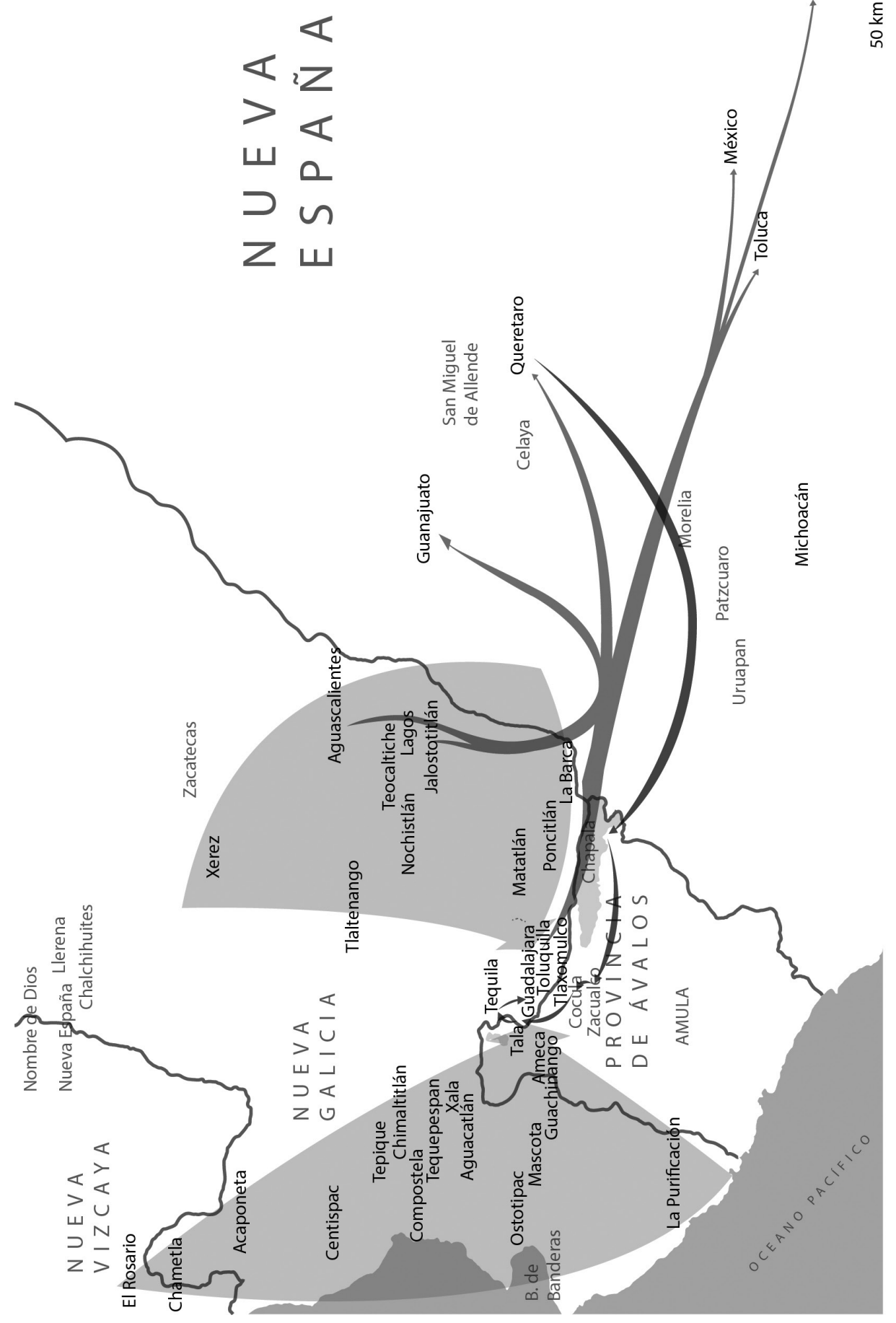

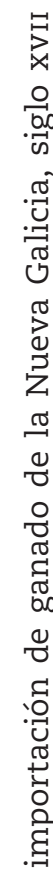

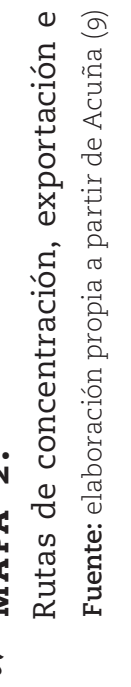

$\begin{array}{lllllllllllllllllll}\text { F } & \mathrm{R} & \mathrm{O} & \mathrm{N} & \mathrm{T} & \mathrm{E} & \mathrm{R} & \mathrm{A} & \mathrm{S} & d e & l a & \mathrm{H} & \mathrm{I} & \mathrm{S} & \mathrm{T} & \mathrm{O} & \mathrm{R} & \mathrm{I} & \mathrm{A}\end{array}$ 
Si se analiza el anexo I, se puede comprender la evolución de las diferentes zonas exportadoras de ganado. Tepic, por ejemplo, junto con Lagos, Guadalajara y Jalostotitlán, están como exportadores en la mayoría de los años aquí estudiados. Acaponeta a partir de I69I no vuelve a presentarse como exportador de ganado, lo que se debió a una sobreexplotación de animales que trajo como consecuencia — según escribió el obispo Garabito en I692- la despoblación de sus estancias ganaderas. Lo mismo le ocurrió a Centispac, aunque este centro desde 1680 había dejado de enviar ganados. Compostela, que se había mantenido remitiendo desde I67I hasta I693, prácticamente dejó de hacerlo después de ese año y solo vuelve a aparecer una vez en el resto del siglo. Otros centros empezaron "tarde" a remitir ganado, pero a partir de i68I se mantuvieron hasta 1700. Estos fueron La Barca, Aguascalientes y Tacotán.

A diferencia del ganado vacuno, que se exportaba en abundancia y de varias regiones, la saca de ganado caballar representó el Io \% del total de animales vendidos al exterior de la Nueva Galicia. La mayor parte provenía de cuatro poblaciones de lo que hoy se conoce como los Altos de Jalisco. La figura 3 muestra el desglose de las cantidades de animales remitidas por cada población, así como el tipo de ganado; solo se apuntaron los que exportaron más de 2.000 cabezas. La columna 3 de esa tabla, que indica mulas y caballos, se debe a que muchas de las licencias no especificaban el tipo de animal y solo señalaban que se trataba de "mulas y caballos". Los cuatro primeros lugares apuntados representan el 68,2 \% del total de caballos y mulas exportados. Si se observa con detalle la figura 3 , no aparece ninguno de los grandes centros criadores de ganado vacuno de los climas calurosos como Acaponeta, Compostela, Centispac, Tepic u otros. Esto confirma el aserto del profesor Serrera respecto a que en los climas fríos predominaba más la cría de ganado caballar y mular (Serrera, "La contabilidad" 2).

5 La carta que el obispo de Guadalajara escribió en 1692 expone la grave escasez de animales en las provincias de Acaponeta, Centispac y Autlán (Calvo, Guadalajara 205). 
- FIGURA 3

Principales lugares de la Nueva Galicia que exportaban mulas y caballos

\begin{tabular}{|l|c|c|c|c|}
\hline \multicolumn{1}{|c|}{ Lugar } & Mulas & Caballos & $\begin{array}{c}\text { Mulas y } \\
\text { Caballos }\end{array}$ & Total \\
\hline Lagos & 7.320 & 10.160 & 4.720 & 22.200 \\
\hline Aguascalientes & 2.502 & 4.919 & 2.100 & 9.521 \\
\hline Teocaltiche & 2.420 & 3.316 & 360 & 6.096 \\
\hline Jalostotitlán & I.320 & 4.350 & I.100 & 4.350 \\
\hline Juchipila & 2.200 & 700 & 650 & 3550 \\
\hline Guadalajara & 1.750 & 1.520 & 200 & 3.470 \\
\hline La Barca & 30 & 435 & 1.620 & 2.085 \\
\hline No indicado & 1.215 & 1.080 & 1.030 & 4,25 \\
\hline
\end{tabular}

Fuente: AIPG, Libros de Gobierno de la Real Audiencia de Guadalajara

\section{Importación de ganado menor}

Para el análisis del comercio de importación de ganado menor la información que se tiene es más cualitativa que cuantitativa. Por diferentes circunstancias, en la Nueva Galicia la introducción de estos animales fue mucho más lenta y poco numerosa que la del ganado mayor. El clima más cálido que en la Nueva España desempeñó un papel determinante para la configuración geográfica de la crianza y reproducción de ganado menor. Al mismo tiempo, la organización territorial de los reinos estableció que extensas regiones muy cercanas a la capital neogallega quedaran fuera de su jurisdicción y pertenecieran a la Nueva España, siendo agrupadas en lo que se conoció como la provincia de Ávalos, y desde ahí se realizó la importación de ganado menor gracias a las miles de cabezas que ańo con ańo llegaban a pastar durante la temporada de invierno.

La poca existencia de ganado menor en la Nueva Galicia se constata por los testamentos de los ganaderos del siglo Xvi, los cuales muestran que apenas llegaban a tener entre 990 y i.50o ovejas (Palomino y Cañedo). De doce relaciones geográficas que se escribieron entre 1579 y 1585 de varias de sus provincias, solo una da fe de la existencia de crianza de ganado menor. Se trata de Tenamaztlán, que en realidad pertenecía a la Nueva España. En ella se informa cómo allí en 
I579 se multiplicaban muy bien las ovejas, aunque no eran tan gordas como otras de la Nueva España. Esto se debía a que la tierra era más caliente que fría y también porque "hay mucha saetilla y cardillo que se pegan a la lana, lo cual debe darles tanta pena que las enflaquece" (Acuña 289). El obispo de Guadalajara Mota y Escobar escribió en 1605 que las cabras no se daban, las ovejas se criaban en poca cantidad y solo entre los indios. El ganado de cerda existía, pero no había criaderos para este (De la Mota y Escobar 28).

Fue después del primer cuarto del siglo Xvir que el ganado menor comenzó a criarse en mayor número, aunque en pocos lugares. Cerca de Guadalajara (40 km), en la jurisdicción de Tala que pertenecía a la Nueva Espańa, el rico ganadero Zeledón González de Apodaca controlaba el abastecimiento de este tipo de animales, y ya para 1630 era capaz de vender en una sola partida la cantidad de Io.000 ovejas (AIPG, "Francisco de Orendain", vol. 2, ff. 3-4 v.). En la región de Lagos y Aguascalientes fue donde mayor desarrollo alcanzó el ganado menor, en especial en la hacienda de Ciénega de Mata que pertenecía a la familia Rincón Gallardo. Para hacerse una idea de la cantidad de ovejas que tenía, considérese que desde el año de 1662 el dueño de esta hacienda aparece solicitando permisos anuales para matar sus ovejas viejas y estériles. En trece años registrados entre I662 y I695 mató un total de 30.000 animales (AIPG, LG, vol. I-7). Durante los primeros años del siglo Xvini, el número de ovejas que poseía pasaba de las 60.000 .

La lenta introducción del ganado menor no impidió que las ciudades y reales de minas neogallegos se abastecieran bien de este tipo de carne por los rebaños de ovejas que año tras año llegaban a pastar a la zona de la ribera del lago de Chapala ${ }^{6}$ y a los pueblos de Poncitlán, La Barca, Atotonilco, Cuitzeo, Ayo el Chico, Ayo el Grande y Colimilla y Matatán. Los animales provenían de Querétaro, Michoacán y la Ciudad de México; los ganaderos poseían tierras en esas poblaciones que destinaban exclusivamente para que sus rebaños agostaran desde el mes de septiembre, que era cuando llegaban, hasta fines de mayo cuando regresaban a su lugar de origen ${ }^{7}$.

6 El clima que provocaba la laguna de Chapala, más húmedo y templado, permitía que los pastos se conservaran durante la época de invierno, a diferencia de lo que ocurría en la Nueva España donde por el clima más frío no se conservaban (De la Mota y Escobar 28).

7 Lázaro de Arregui afirmaba que esta trashumancia representaba mucho provecho para esos pueblos, aunque no se realizara ahí la trasquila (Arregui ir3). 
En esos límites extrafronterizos de la Nueva Galicia, específicamente en la provincia de Ávalos y las jurisdicciones de Tala, Eztatlán y Ameca, se dio desde fines del siglo xvi una gran demanda y acaparamiento de tierra (rentada o comprada) por parte de los ganaderos de la Nueva España, para ser destinada al pastoreo. En el archivo notarial de Guadalajara existen numerosos ejemplos de la primera mitad del xvir. Así, se puede ver a un Marcos García que desde i6I4 comenzó a rentar una estancia en el valle de Tala para llevar allí a sus ovejas y carneros que traía desde Querétaro (BPEJ, $R A G, B D$, caj. 287, exp. 59, prog. 3196). Tres años después lo vemos comprando 16 sitios de ganado menor y 2,5 de mayor entre los pueblos de Cocula y Zacoalco, a donde llevó desde aquella ciudad I3.000 ovejas y cabras (AIPG, TA, t. 62, leg. 39, exp. 2, ff. 83-88). Hacia I632 otro ganadero de Querétaro rentó I2 sitios de ganado mayor y menor en los pueblos de Atotonilco, Zacoalco, Cocula y San Martín para el mismo fin (AIPG, "Francisco de Orendain”, vol. 3 , ff. 53 v.-54 v.). Por esos años, el valor del arrendamiento de un sitio de ganado mayor destinado a pastoreo rondaba entre los 30 y los 35 pesos, aunque a fines del Xvir había subido unos io pesos, aproximadamente . $^{8}$

Los jesuitas de otras partes de la Nueva España se insertaron también en este circuito comercial. A pesar de que poseían muchas tierras, otras las rentaban con el único objetivo de llevar allí sus rebaños durante la época de invierno. Al menos en una ocasión, los del colegio de San Gregorio de la Ciudad de México rentaron durante nueve años la hacienda de San Nicolás en Tequila para que a ese lugar llegaran a pastar sus ovejas (AIPG, "José Antonio Calleja”, vol. I, f. 222)9. Los de Valladolid, en cambio, poseían 23 sitios de ganado mayor, uno de menor y 24 caballerías de tierra en el pueblo de Cocula que utilizaban únicamente como agostadero ${ }^{\text {Io }}$.

Quizá el mejor ejemplo de estos estancieros que trasladaban su ganado menor a las cercanías de Nueva Galicia sea el del capitán Alonso de Estrada Altamirano, vecino también de Querétaro, quien desde el último tercio del siglo XVII comenzó rentando tierras por las que pagaba 500 pesos anuales hasta que optó por ir comprando en varios lugares, aunque solo las utilizara seis meses al

8 Varios ejemplos de arrendamientos de tierra para fines de pastoreo pueden consultarse en AIPG, "Francisco de Orendain", vol. 4, f. 39; Miguel de Ascoide, vol. I, ff. I37 v.-139; José Antonio Calleja, vol. I, ff. 222 y $225-226$.

9 El precio de renta anual fue de roo pesos.

Io Anteriormente esa tierra había pertenecido a Agustín de Osio y Ocampo, vecino de la ciudad de Celaya, que también la utilizaba para que sus ovejas llegaran a pastar durante la temporada de fríos

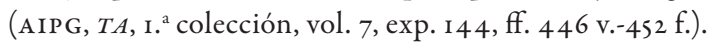


año (вреJ, $R A G, R C$, caj. 8, exp. I6, prog. -II2). Para fines de esa centuria poseía ya 56 sitios de ganado mayor, 36 de menor y 165 caballerías de tierra. Con ellas formó el mayor corredor de tierras de pastoreo en la Nueva Galicia. La mayoría se localizaban en La Barca y Poncitlán, pero se extendían a Colimilla y Matatán, Tlajomulco, Tala y Tequila (AIPG, TA, I. ${ }^{a}$ colección, vol. 7, exp. 46, ff. IO4-I3I).

Esta trashumancia de más de $500 \mathrm{~km}$ fue descrita por fray Alonso Ponce en I584 al ser testigo de la llegada de numerosos rebaños que venían de Querétaro y México a pastar a las orillas del lago de Chapala y a otras regiones cercanas a Guadalajara como Etzatlán, Zacoalco, Tacotlán, Colimilla y Matatán (Arregui 62 y 145-155). Chevalier calculó que eran más de 200.000 ovejas que año con año iban a pastar a la zona de la ribera de Chapala (Chevalier I83). En los libros de cabildo de la ciudad de Guadalajara se asienta que en el año de I629, por concepto del impuesto cobrado a los ganados menores que llegaban a agostar, se obtuvo un ingreso de I.00o pesos. La tarifa que cobraban era de un peso por cada cien cabezas, de modo que en ese ańo agostaron en la Nueva Galicia unas Ioo.0oo cabezas (Ayuntamiento, vol. I, 345).

Los encargados del abasto de la ciudad de Guadalajara aprovechaban la temporada que llegaba el ganado menor para comprar los animales suficientes para cubrir la demanda interna. No mataban inmediatamente todo el ganado, sino que tenían algunas tierras donde lo guardaban y, conforme a la necesidad, así era el número que se sacrificaba. Algunos de ellos recibieron repartimiento de mano de obra indígena que destinaban al cuidado de esos animales. Al menos en I622, se dieron en dos ocasiones a favor del obligado del abasto para que cuidaran sus carneros que tenían pastando en los pueblos de Cuyutlán y Cajititlán (Jiménez 460).

Los precios a los que se vendían los carneros en Guadalajara no variaron mucho durante la primera mitad del siglo xvir. En 1605 un carnero en pie costaba entre I4 y i6 reales. Al menudeo, la carne se vendía a dos libras y media por un real (De la Mota y Escobar 28). En I6I5, Lázaro Domínguez Delgado, encargado del abasto de carne de res y carnero para la ciudad de Guadalajara, compró 8.600 carneros a un ganadero de Querétaro que tenía sus rebaños agostando en el pueblo de Etzatlán. Pagó por ellos 15.050 pesos de oro común a razón de I4 reales cada uno (AIPG, "Andrés Venegas", vol. I, ff. II7-II9). En I62I, el precio de los carneros en pie había bajado un real (Arregui 85). 


\section{Reflexiones finales}

Intentar analizar exclusivamente el circuito comercial de exportación e importación en la Nueva Galicia durante el siglo XviI representa un gran reto, sobre todo en el marco de un artículo, pues surge de manera espontánea una amplia variedad de temas que solo pueden ser esbozados, algunos, en tanto que otros se tienen que dejar de lado aunque se quiera abordarlos. Por ejemplo, falta abundar si las fluctuaciones de las exportaciones aquí presentadas se deben a los ciclos naturales de crianza o a la simple ausencia de información de la época. Se antoja estudiar la evolución de los precios a lo largo de toda esa centuria y compararlos con los que se vendían en el mercado interno. De esa forma se entendería mejor la alta exportación de ganado.

Es verdad que el tema de las condiciones climáticas, que determinó las zonas criadoras y exportadoras, es sumamente relevante. Intentamos abordarlo tanto como la fuente nos lo permitió, pero se requeriría otra investigación más profunda al respecto y que por sí sola merecería un estudio aparte. Lo mismo ocurre si intentamos analizar la estructura social de este negocio pues haría falta un estudio prosopográfico de los dueños de ganado, criadores, transportistas, compradores, agentes financieros, entre otros, estudio relevante que sobrepasa el espacio de un artículo.

Creemos que al menos logramos, en esencia, exponer por primera vez cómo se formó y funcionó el circuito mercantil de exportación e importación de animales en la Nueva Galicia durante el siglo xviI, pero sobre todo pudimos explicar que ante la importancia económica que alcanzaron, las distintas autoridades civiles y eclesiásticas supieron insertarse tanto en la recaudación de impuestos como para beneficiarse con la venta directa en el exterior del reino. 
$\rightarrow$ ANEXO I

Exportación de ganado de la Nueva Galicia

\begin{tabular}{|c|c|c|c|c|c|c|c|c|c|c|c|c|c|c|c|c|c|c|}
\hline Lugar & ్ㅡㅁ & ్ㅡㅁ & ํㅡ & $\sqrt{6}$ & $\underset{n}{\infty}$ & $\frac{2}{6}$ & छి & $\underset{6}{6}$ & ర్రి & $\underbrace{\infty}_{0}$ & రి & $\sqrt{6}$ & $\underset{1}{N}$ & $\frac{n}{6}$ & $\underset{6}{*}$ & $\underset{n}{n}$ & $\stackrel{0}{6}$ & $\hat{\sigma}$ \\
\hline Acaponeta & & & & & & & & $\begin{array}{l}8 \\
\dot{m} \\
\dot{m}\end{array}$ & & 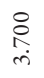 & & $\begin{array}{l}8 \\
\stackrel{0}{0} \\
\text { i }\end{array}$ & $\stackrel{\infty}{\infty}$ & $\begin{array}{l}8 \\
8 \\
\dot{0} \\
\text { in }\end{array}$ & $\begin{array}{l}8 \\
i n \\
i\end{array}$ & $\begin{array}{l}8 \\
\stackrel{+}{+} \\
\dot{r}\end{array}$ & $\stackrel{\circ}{\stackrel{n}{n}}$ & \\
\hline Aguascalientes & & & & \& & $\stackrel{\circ}{\infty}$ & & & $\begin{array}{l}8 \\
\stackrel{8}{n} \\
\end{array}$ & : & & $\begin{array}{l}\text { \& } \\
\text { ¿ } \\
\text { : }\end{array}$ & & & & & ஓ̊ & & \\
\hline \multicolumn{19}{|l|}{ Ahuacatlán } \\
\hline \multicolumn{19}{|l|}{ Ameca } \\
\hline Cestispac & & & & & $\begin{array}{l}8 \\
\text { D } \\
\text { ri }\end{array}$ & & & $\begin{array}{l}\stackrel{0}{6} \\
\stackrel{+}{+}\end{array}$ & & & & 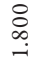 & & & $\begin{array}{l}\text { ì } \\
\text { in }\end{array}$ & & & \\
\hline $\begin{array}{c}\text { Colimilla y } \\
\text { Matatán }\end{array}$ & & & & & & & & & & & & & & & $\stackrel{8}{\rightleftarrows}$ & $\stackrel{\circ}{\stackrel{\infty}{\infty}}$ & & \\
\hline Compostela & & & & 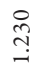 & & & $\stackrel{8}{\stackrel{2}{2}}$ & & $\begin{array}{l}\stackrel{8}{0} \\
\dot{r}\end{array}$ & & $\begin{array}{l}\stackrel{8}{\infty} \\
\text { in } \\
i\end{array}$ & $\stackrel{n}{\stackrel{2}{a}}$ & $\begin{array}{l}\stackrel{8}{\infty} \\
\infty \\
+i\end{array}$ & $\begin{array}{l}\stackrel{\curvearrowright}{\hat{n}} \\
\text { in }\end{array}$ & $\begin{array}{l}8 \\
\infty \\
+ \\
+\end{array}$ & $\begin{array}{l}\stackrel{8}{\circ} \\
\infty \\
+i\end{array}$ & 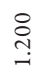 & $\begin{array}{l}\stackrel{\circ}{8} \\
\stackrel{\circ}{i}\end{array}$ \\
\hline Chametla & & & & & $\begin{array}{l}\stackrel{8}{0} \\
\text { i }\end{array}$ & & & & & & $\begin{array}{l}\stackrel{\circ}{+} \\
\stackrel{+}{+}\end{array}$ & & & & & & & \\
\hline \multicolumn{19}{|l|}{ Chistlán } \\
\hline Jala & & & & & & & $\begin{array}{l}\stackrel{8}{\text { + }} \\
\text { i }\end{array}$ & & & & & & & & & & $\begin{array}{c}8 \\
i n \\
i n\end{array}$ & \\
\hline La Barca & & & & & & & & : & & & & & & & & & & \\
\hline Lagos & $\begin{array}{l}\stackrel{8}{\Xi} \\
\text { i }\end{array}$ & 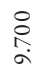 & $\begin{array}{l}\stackrel{8}{8} \\
\dot{+}\end{array}$ & & & & & & & $\stackrel{1}{\gtrless}$ & & & in & ถึ & & & & \\
\hline Guachinango & & & & & & & & & & $\stackrel{\text { }}{\stackrel{一}{-}}$ & \& & & & & & & & \\
\hline Guadalajara & $\begin{array}{l}8 \\
\vdots \\
\dot{0}\end{array}$ & 兓 & & & & & & $\begin{array}{l}8 \\
\stackrel{8}{\infty} \\
-1\end{array}$ & 䓍 & 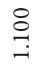 & $\underset{\substack{n \\
+}}{+}$ & & $\begin{array}{l}8 \\
\stackrel{0}{4}\end{array}$ & & $\begin{array}{l}8 \\
\text { in } \\
\text { in }\end{array}$ & $\begin{array}{l}\stackrel{\Xi}{\check{r}} \\
\dot{m}\end{array}$ & $\frac{8}{i}$ & 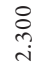 \\
\hline \multicolumn{19}{|l|}{ Ixtlahuacán } \\
\hline Jalostotitlán & $\stackrel{8}{\circ}$ & & & $\underset{+}{\stackrel{+}{+}}$ & & $\begin{array}{l}\stackrel{8}{0} \\
\tilde{i}\end{array}$ & $\stackrel{\text { in }}{=}$ & 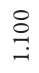 & $\stackrel{8}{\stackrel{0}{2}}$ & & & & $\stackrel{\circ}{\stackrel{n}{=}}$ & $\underset{+}{\stackrel{+}{8}}$ & $\stackrel{\infty}{\infty}$ & $\underset{n}{\stackrel{n}{n}}$ & $\stackrel{\circ}{n}$ & \\
\hline Jerez & & & & & & & & & & & & & & & & & & \\
\hline \multicolumn{19}{|l|}{ Juchipila } \\
\hline Mascota & & & & & & & & & & & & & & & & & & \\
\hline
\end{tabular}




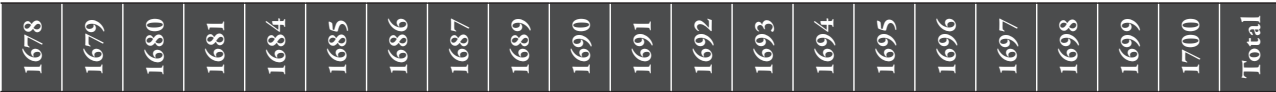

\begin{tabular}{|c|c|c|c|c|c|c|c|}
\hline 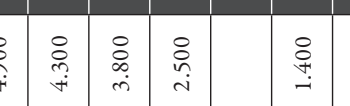 & 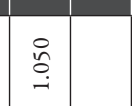 & 里 & & & & & 量 \\
\hline 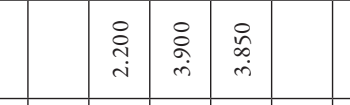 & 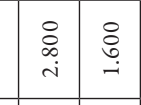 & 多年 & & 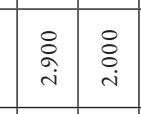 & 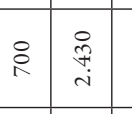 & & \\
\hline 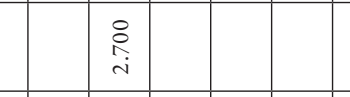 & & & & & & & \\
\hline
\end{tabular}

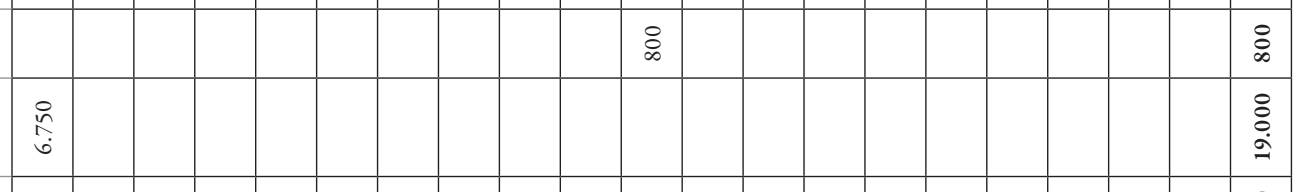

\begin{tabular}{|c|c|c|c|c|c|c|c|c|c|c|c|c|c|c|c|c|c|c|c|c|}
\hline & & & & $\stackrel{8}{\beth}$ & $\stackrel{\infty}{\infty}$ & ঙ̊. & 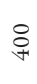 & ঃ্̀ & & : & & in & & 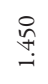 & : & $\stackrel{\circ}{\stackrel{\infty}{\leftrightarrows}}$ & : & & & $\begin{array}{l}0 \\
\infty \\
\stackrel{3}{\simeq} \\
\end{array}$ \\
\hline & 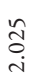 & 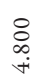 & & $\begin{array}{l}\stackrel{8}{0} \\
\dot{0}\end{array}$ & 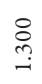 & $\begin{array}{l}\dot{n} \\
b \\
\dot{r n}\end{array}$ & & & $\begin{array}{l}\stackrel{\leftrightarrow}{\mathbf{N}} \\
\text { in }\end{array}$ & 帝 & $\stackrel{?}{\stackrel{7}{6}}$ & 旾 & & & & \begin{tabular}{l}
8 \\
\multirow{0}{0}{} \\
$\stackrel{+}{*}$
\end{tabular} & & & & 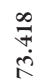 \\
\hline$\underset{\forall}{\stackrel{\Xi}{\leftrightarrows}}$ & & $\begin{array}{l}\stackrel{8}{0} \\
\stackrel{m}{n}\end{array}$ & $\begin{array}{l}0 \\
\hat{\infty} \\
\dot{r}\end{array}$ & $\begin{array}{l}8 \\
\stackrel{2}{2} \\
\end{array}$ & & & ¿ & & & $i$ & & & & & : & & & & & 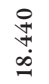 \\
\hline & & & & & & & & & & & & & & & 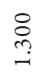 & & & & & $\stackrel{8}{\stackrel{0}{2}}$ \\
\hline & & & & & $\underset{-}{\circ}$ & ¿े & & & & & & & & & & & & & & $\begin{array}{l}\stackrel{8}{0} \\
\infty \\
\stackrel{0}{0}\end{array}$ \\
\hline & & : & & & : & & & 辛 & $\begin{array}{c}\hat{\sigma} \\
\hat{n}\end{array}$ & $\begin{array}{l}\stackrel{8}{0} \\
\stackrel{i}{i}\end{array}$ & \begin{tabular}{l}
0 \\
\multirow{6}{\hat{~}}{} \\
$i$
\end{tabular} & 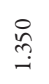 & $\underset{i}{\stackrel{O}{i}}$ & 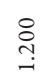 & $\begin{array}{l}\stackrel{n}{n} \\
\hat{n}\end{array}$ & ڤু & $\begin{array}{l}\stackrel{0}{0} \\
\stackrel{i}{i}\end{array}$ & $\stackrel{\circ}{\circ}$ & : & $\begin{array}{c}\text { ஸे } \\
\text { ते }\end{array}$ \\
\hline : & : & 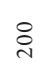 & & $\begin{array}{l}\stackrel{0}{\hat{i}} \\
\text { in }\end{array}$ & 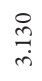 & 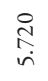 & 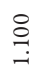 & 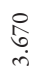 & $\begin{array}{l}8 \\
\stackrel{0}{0} \\
\text { in }\end{array}$ & $\begin{array}{l}\infty \\
\infty \\
i n\end{array}$ & $\underset{\substack{\hat{f} \\
\dot{n}}}{ }$ & 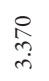 & $\begin{array}{l}\stackrel{0}{+} \\
\stackrel{+}{+}\end{array}$ & 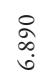 & 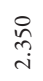 & 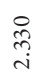 & $\begin{array}{l}\stackrel{\infty}{\infty} \\
\stackrel{\sim}{\sim}\end{array}$ & 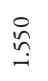 & $\begin{array}{l}\text { Dे } \\
\text { in }\end{array}$ & 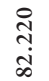 \\
\hline & & & & & $\underset{\infty}{\infty}$ & 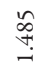 & $\underset{\mathrm{i}}{\stackrel{8}{\mathrm{i}}}$ & $\stackrel{\infty}{\infty}$ & & & & & & & & & & 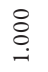 & & 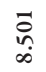 \\
\hline & & : & & $\begin{array}{l}\stackrel{8}{0} \\
\text { r. }\end{array}$ & $\underset{\substack{\tilde{y} \\
+}}{ }$ & & $\begin{array}{l}\stackrel{2}{\circ} \\
\stackrel{+}{+}\end{array}$ & 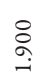 & 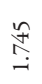 & 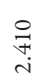 & $\begin{array}{l}\stackrel{\leftrightarrow}{1} \\
\text { nִ }\end{array}$ & $\begin{array}{l}0 \\
\stackrel{0}{0} \\
i\end{array}$ & $\begin{array}{l}8 \\
\text { +े } \\
\text { m. }\end{array}$ & $\begin{array}{l}\stackrel{0}{n} \\
i \\
i\end{array}$ & & $\begin{array}{l}\stackrel{\circ}{\circ} \\
\stackrel{-}{-}\end{array}$ & $\begin{array}{l}\stackrel{P}{f} \\
\stackrel{+}{i}\end{array}$ & 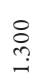 & 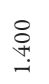 & $\frac{0}{7}$ \\
\hline & & & & 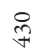 & $\stackrel{m}{m}$ & & & & & & & & & & & & & & & $\stackrel{\infty}{\infty}$ \\
\hline & $\stackrel{̊}{\leftrightarrows}$ & 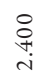 & 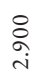 & $\begin{array}{l}\stackrel{n}{n} \\
\text { in }\end{array}$ & & & : & $\begin{array}{l}\stackrel{0}{\circ} \\
\stackrel{n}{m}\end{array}$ & $\ddot{\infty}$ & 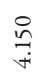 & $\begin{array}{l}\stackrel{8}{ } \\
\dot{\alpha} \\
\dot{n}\end{array}$ & $\begin{array}{l}\stackrel{i}{n} \\
\stackrel{n}{n}\end{array}$ & $\begin{array}{l}\stackrel{\sim}{n} \\
\underset{n}{n}\end{array}$ & 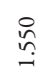 & ষ্ণ & & & & in & \begin{tabular}{l}
0 \\
\multirow{6}{0}{} \\
ț
\end{tabular} \\
\hline & & & & & & & & & & & & & & & $\stackrel{\sim}{\sim}$ & 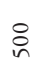 & 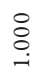 & & & $\stackrel{\stackrel{n}{r}}{\text { r }}$ \\
\hline & & : & & & & & & 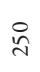 & & 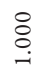 & $\begin{array}{l}\stackrel{0}{0} \\
\hat{o} \\
i\end{array}$ & $\stackrel{2}{\circledR}$ & & & $\begin{array}{l}8 \\
\infty \\
i \\
i\end{array}$ & 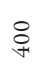 & 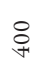 & & 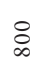 & $\begin{array}{l}\stackrel{0}{0} \\
\dot{0}\end{array}$ \\
\hline & & & & & & & & & & $\begin{array}{l}\text { } \\
\infty \\
\infty\end{array}$ & \&̊ & & & & & & & & & Pُ \\
\hline
\end{tabular}




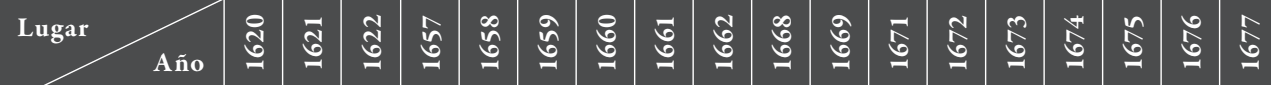

Nochistlán

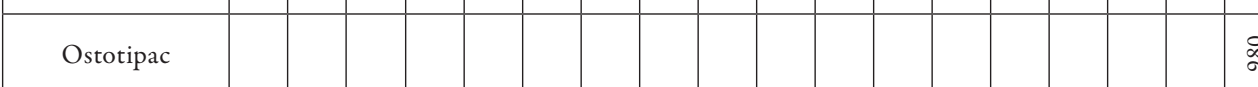

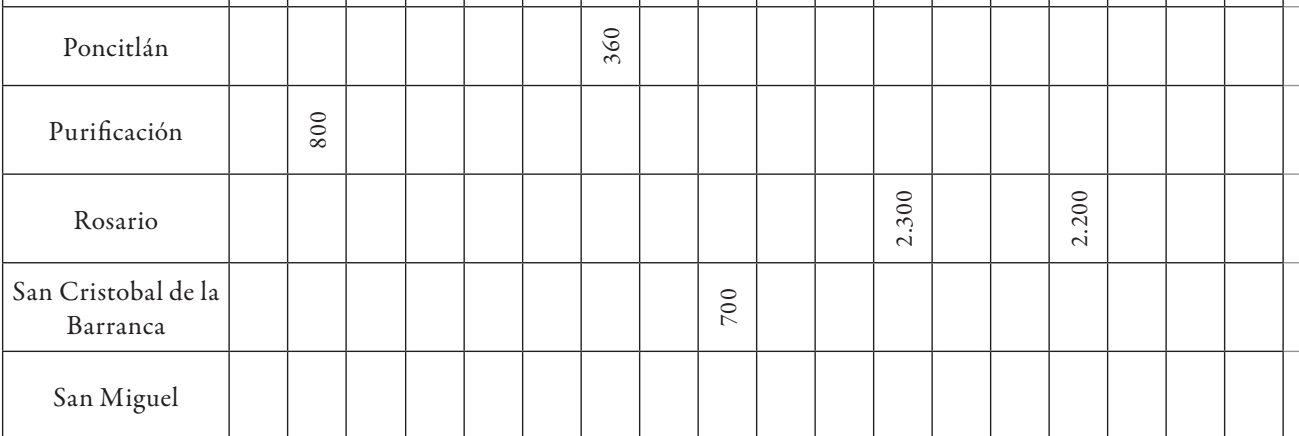

\begin{tabular}{|c|c|c|c|c|c|c|c|c|c|c|c|c|c|c|c|c|c|c|}
\hline Sierra de Pinos & & & & & & & & & $\stackrel{8}{1}$ & & & & & & & & & \\
\hline Sombrerete & & & & & & & & & & & & & & & & & & \\
\hline Tacotán & & & & & & & & & & & in & & $\stackrel{i}{n}$ & & 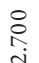 & & & \\
\hline Teocaltiche & & & & & & & & & & & & & & & & \& & & \\
\hline Tepatitlán & & & & & & & in & & & & & & & & & & & \\
\hline Tequepexpan & & & & & & & & & & & & $\begin{array}{l}\stackrel{0}{\circ} \\
\stackrel{+}{+} \\
\text { i }\end{array}$ & & & $\begin{array}{l}\stackrel{0}{6} \\
\stackrel{6}{i}\end{array}$ & $\begin{array}{l}\stackrel{8}{8} \\
\stackrel{0}{0} \\
\text { i }\end{array}$ & & \\
\hline Tepic & & & & & & & & & & $\stackrel{8}{\stackrel{\overbrace{}}{2}}$ & $\begin{array}{l}8 \\
\text { ¿ } \\
\text { i }\end{array}$ & & & & & & $\begin{array}{l}8 \\
\infty \\
i\end{array}$ & \\
\hline Tesistán & & & & & & & & $\stackrel{\circ}{\circ}$ & & & & & & & & & & \\
\hline Tlaltenango & & & & & & & & & & & & & & & & & & \\
\hline $\begin{array}{l}\text { V. Trujillo } \\
\text { Fresnillo }\end{array}$ & & $\begin{array}{l}8 \\
8 \\
\dot{0}\end{array}$ & & & & & & & & & & & & & & & & \\
\hline Zacatecas & & & & & & & & & & & & & & & & & & \\
\hline N.I & $\stackrel{8}{\stackrel{+}{+}}$ & 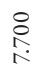 & & & & $\begin{array}{l}\stackrel{\text { }}{ } \\
\dot{0} \\
\dot{m}\end{array}$ & $\underset{\forall}{\stackrel{8}{\circ}}$ & & $\begin{array}{l}8 \\
\stackrel{2}{n} \\
\text { in }\end{array}$ & $\begin{array}{l}\stackrel{0}{\hat{\sigma}} \\
\stackrel{i}{i}\end{array}$ & 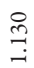 & & & & & & & \\
\hline Total & 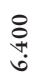 & 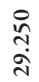 & 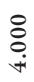 & 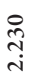 & 華 & $\stackrel{8}{\stackrel{\leftrightarrow}{n}}$ & $\begin{array}{l}\stackrel{8}{0} \\
\stackrel{1}{0}\end{array}$ & $\stackrel{?}{\stackrel{0}{*}}$ & $\underset{\stackrel{̊}{\circ}}{\infty}$ & 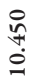 & 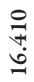 & 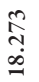 & $\stackrel{\circ}{\stackrel{R}{̊}}$ & $\begin{array}{l}\text { Ò } \\
\text { Ṅ } \\
\text { I }\end{array}$ & 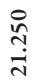 & $\begin{array}{l}\text { in } \\
\text { i. }\end{array}$ & \begin{tabular}{l}
$\stackrel{8}{\circ}$ \\
\} & $\begin{array}{l}\stackrel{8}{\infty} \\
\stackrel{i}{n} \\
\text { in }\end{array}$ \\
\hline
\end{tabular}
\end{tabular}

Fuente: AIPG, Libros de Gobierno de la Real Audiencia de Guadalajara. 


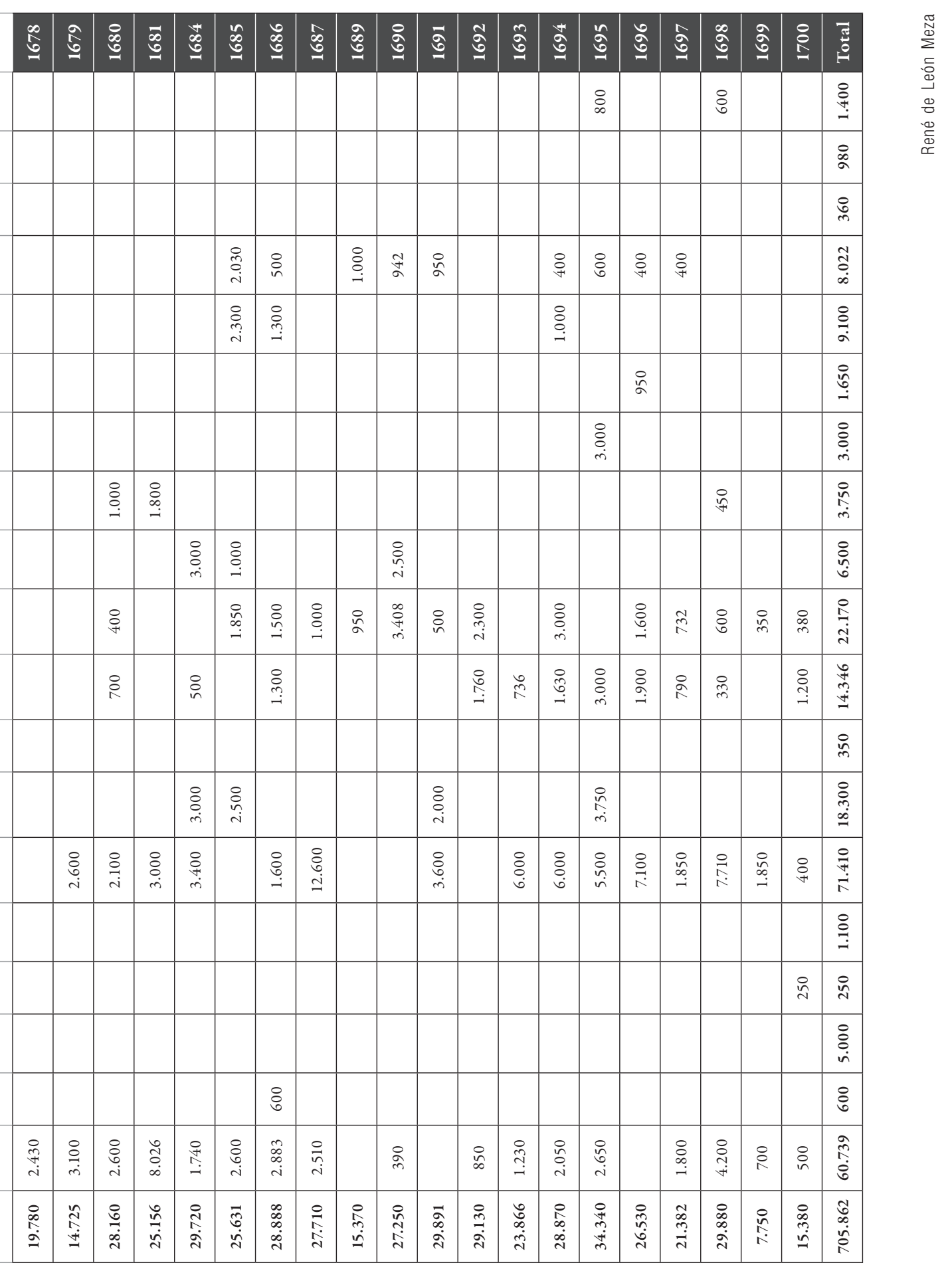




\section{$\infty$ \\ B I B L I O G R A F í A}

\section{I . F U E N T ES PRIMARIAS}

\section{A. Archivos}

Archivo de Instrumentos Públicos de Guadalajara (AIPG).

Libros de Gobierno ( $L G$ ).

Tierras y Aguas (TA).

Notarios (N).

Archivo General de Indias, Sevilla, España (AGI).

Mapoteca (M).

Cartas de Audiencia (CA).

Biblioteca Pública del Estado de Jalisco, México (BPEJ).

Real Audiencia de Guadalajara (RAG).

Bienes de Difunto (BD).

Ramo Civil (RC).

Instituto Cultural Ignacio Dávila Garibi (ICDG).

\section{B. Impresos}

Actas de Cabildos de la ciudad de Guadalajara, 2 vols. Guadalajara: Ayuntamiento de Guadalajara, Instituto Jalisciense de Antropología e Historia, INAH, 1970.

Acuña, René, ed. Relaciones geográficas del siglo XVI: Nueva Galicia. México: UnA M, I988.

Arregui, Domingo Lázaro de. Descripción de la Nueva Galicia Siglo XVII. Guadalajara: Unidad Editorial del Gobierno del estado de Jalisco, 1980.

Berthe, Jean-Pierre, Thomas Calvo y Águeda Jiménez Pelayo. Sociedades en construcción. La Nueva Galicia según las visitas de los oidores (I606-I6I6). Guadalajara: Universidad de Guadalajara y Centre Français d'Etudes Mexicaines et Centroaméricaines, 2000.

Dávila Garibi, José Ignacio. Apuntes para la historia de la iglesia en Guadalajara, 6 vols.

México: Editorial Cultura, T.G, 196r. 
De la Mota y Escobar, Alonso. Descripción geográfica de los reinos de Nueva Galicia, Nueva Vizcaya y Nuevo León. Guadalajara: Universidad de Guadalajara, Instituto Jalisciense de Antropología e Historia, Unidad Editorial del Gobierno del Estado de Jalisco, 1993.

Fernández Sotelo, Rafael-Diego. La primigenia Audiencia de la Nueva Galicia 1548-1572. México: El Colegio de Michoacán, Cámara de Comercio de Guadalajara, 1993.

Palomino y Cañedo, Jorge. Los protocolos de Rodrigo Hernández Cordero, I58I-I59I. Escribano público de Guadalajara. Guadalajara: Banco Industrial de Jalisco, 1972.

\section{I F U E N T ES SECUNDARIAS}

Arévalo Vargas, Lucía. Historia de la provincia de Ávalos, virreinato de la Nueva España. Guadalajara: Universidad de Guadalajara, Instituto Jalisciense de Antropología e Historia, 1979.

Calvo, Thomas. Guadalajara y su región en el siglo XVII. Población y economía. Guadalajara: Ayuntamiento de Guadalajara, 1992.

---. “Japoneses en Guadalajara: blancos de honor durante el seiscientos mexicano”. Revista de Indias, vol. XLIII, n. ${ }^{\circ}$ I72, 1983 , pp. 533-547.

--.. "Un extraño señor de ganados: el maese de campo don Francisco de Pareja y Rivera". Revista Encuentro, vol. 3, n. ${ }^{\circ}$, pp. 5-19.

Chevalier, François. La formación de los latifundios en México. Haciendas y sociedad en los siglos XVI, XVII y XVIII. México: Fondo de Cultura Económica, I999.

Jiménez Pelayo, Águeda. "Condiciones del trabajo de repartimiento indígena en la Nueva Galicia en el siglo Xviı”. Historia Mexicana, vol. XXXVIII, n. ${ }^{\circ}$ 3, I989, pp. 455-470.

Parry, John H. La Audiencia de Nueva Galicia en el siglo XVI: estudio sobre el gobierno colonial español. Zamora: El Colegio de Michoacán, Fideicomiso Teixidor, 1993.

Serrera, Ramón María. "La contabilidad fiscal como fuente para la historia de la ganadería: el caso de Nueva Galicia”. Historia Mexicana, vol. Xxiv, n. ${ }^{\circ}$ 2, 1974, pp. 177-205.

--.. Guadalajara ganadera. Estudio regional novohispano (I760-I805). Guadalajara: Ayuntamiento de Guadalajara, I991.

Van Young, Eric. La ciudad y el campo en el México del siglo XVIII. La economía rural de la región de Guadalajara, 1675-1820. México: Fondo de Cultura Económica, 1989. 